\title{
CALL FOR PARTICIPATION
}

\section{ADVANCES IN COMPUTER CHESS 8}

June 27-28, 1996

Maastricht, The Netherlands

The eighth conference on Advances in Computer Chess will be held in Maastricht, the Netherlands, at Castle Vaeshartelt, $5 \mathrm{~km}$ from Maastricht centre and within the suburbs of that city. The conference commences on Thursday June 27 at 10.30 hours and will end on Friday June 28 at 16.30 hours.

The programme includes several prominent speakers in the computer-chess research field.

\section{Accommodation}

Accommodation is available at Castle Vaeshartelt (Dfl. 115,- for a single room with shower and toilet, breakfast included) and guaranteed if booked before March 27, 1996.

\section{Organising Committee \\ Jaap van den Herik (Chair) \\ Tons van den Bosch \\ Johanna Hellemons \\ Sabina Vanhouwe}

\section{Fees}

We can offer the following arrangements:

$\begin{array}{ll}\begin{array}{l}\text { Early } \\ \text { (before }\end{array} & \begin{array}{l}\text { LatelOn-site Entitlements } \\ \text { (after }\end{array}\end{array}$

June 1, 1996) May 31, 1996)

Dfl. 450,- Dfl. 500.- attendance at all invited lectures and technical sessions, hotel accommodation (a single room for 1 night from June 27 till June 28), breakfast, 2 lunches, refreshments, 1 dinner and a copy of the conference proceedings

Dfl. 350.- Dfl. 400.- $\quad$ attendance at all invited lectures and technical sessions, 2 lunches, refreshments, 1 dinner and a copy of the conference proceedings

Dfl. 250.- Dfl. 300.- attendance at all invited lectures and technical sessions, 2 lunches,

Dfl. 210.- $\quad$ Dfl. 260.refreshments, 1 dinner

attendance at all invited lectures and technical sessions, 2 lunches, refreshments

To register for the conference, please return the enclosed registration form by postal mail, fax or e-mail to Tons van den Bosch. The registration fee is to be paid in Dutch Guilders at the registration desk at June 27, 1996 by cash, traveller's cheque or Eurocheque.

\section{Cancellations}

The registration, especially if including a commitment for a night's stay and lunches, is close to irrevocable: the particular conditions of the excellent château accommodation at Castle Vaeshartelt require the organizing committee to book, without costly revocation fees, into the Castle at an early date, with a limited range of possible reimbursements.

After April 26, 1996

After May 26, 1996

After June 12, 1996

After June 19, 1996 payment of $35 \%$ of the registration fee is due. payment of $60 \%$ of the registration fee is due. payment of $85 \%$ of the registration fee is due. payment of $100 \%$ of the registration fee is due. 


\section{Proceedings}

The proceedings will be edited by Jaap van den Herik, Bob Herschberg and Jos Uiterwijk and published by the University of Limburg. They are expected to be published in January 1997. During the conference, participants can order (additional) copies at the special rate of Dfl. 110.-. The post-conference price of the proceedings will be Dfl. 135.-

\section{More information:}

Tons van den Bosch

University of Limburg

Department of Computer Science

P.O. Box 616

or if preferred

Phone: +31433883477

6200 MD Maastricht

Fax: +31433252392

The Netherlands

E-mail: bosch@cs.rulimburg.nl

Please (e)mail or fax the form below to: Tons van den Bosch, University of Limburg, Department of Computer Science, P.O. Box 616, 6200 MD Maastricht, The Netherlands, fax +31 43 3252392, e-mail: bosch@cs.rulimburg.nl.

\section{Registration form ACC8}

Name:

Postal address:

Phone:

Fax:

E-mail:

Please mark the arrangement of your choice:

0 attendance at all invited lectures and technical sessions, hotel accommodation (a single room for 1 night, from June 27 till June 28), breakfast, 2 lunches, refreshments, 1 dinner and a copy of the conference proceedings

0 attendance at all invited lectures and technical sessions, 2 lunches, refreshments, 1 dinner and a copy of the conference proceedings

0 attendance at all invited lectures and technical sessions, 2 lunches, refreshments, 1 dinner

0 attendance at all invited lectures and technical sessions, 2 lunches, refreshments

Please book additional hotel accommodation at Castle Vaeshartelt at Dfl. 115,- per night from (arrival) till 